\title{
AUTOCAD: EXAMINATION OF FACTORS INFLUENCING USER ADOPTION
}

\author{
ANNA BAJ-ROGOWSKA
}

\begin{abstract}
A B S T R A C T
The primary purpose of the research is to examine and validate determinants of user intention to use AutoCAD software, utilising the constructs from prior studies in a more integrated model. The paper proposes a revised Technology Acceptance Model (TAM) for measuring the adoption of AutoCAD. In the study, a latent construct PPA (perceived physical accessibility) was added to the proposed research model as a new determinant of AutoCAD adoption. An online survey of AutoCAD users was conducted to collect data. This data was empirically used to test the proposed research model. The Structural Equation Modelling (SEM) technique was used to evaluate the causal model, and the confirmatory factor analysis was performed to examine the reliability and validity of the measurement model. The study results show that user behavioural intention to use AutoCAD is significantly affected by three determinants: perceived usefulness, perceived ease of use and perceived physical accessibility of the software. This finding contributes to an expanded understanding of the factors that promote acceptance of AutoCAD software. Moreover, the main contribution of this study is to verify the impact of the added PPA variable on the behavioural intention to use and the actual use of AutoCAD, and also to create measurement scales for this new latent variable in TAM.
\end{abstract}

KEY WORDS

Technology Acceptance Model, TAM, AutoCAD software, the determinants of IT adoption, IT accessibility

10.2478/emj-2020-0004
Corresponding author:

Anna Baj-Rogowska

Gdańsk University of Technology, Poland ORCID 0000-0002-8694-4461 e-mail: anna.baj-rogowska@zie.pg.gda.pl

\section{INTRODUCTION}

Considering the rapid growth of the use of information technologies (IT) in business and in such areas as engineering, the subject of acceptance and evaluation of AutoCAD software used by engineers in the process of designing deserves special attention. An understanding of what determines the adoption of software may provide information that will contribute to the promotion of its success.

The problems related to the promotion and analysis of IT applications are among the leading fields of business informatics studies. The theories proposed in

Citation: Baj-Rogowska, A. (2020). AutoCAD: examination of factors influencing user adoption. Engineering Management in Production and Services, 12(1), 45-56. doi: 10.2478/emj-2020-0004 
this area concentrate on explaining the success and failure drivers related to the implementation of different types of software in organisations, as well as on looking for determinants that facilitate or obstruct the IT adoption by organisations and individual users.

In research, IT adoption is most often explained using the Technology Acceptance Model (TAM). It evolved from the Theory of Reasoned Action (TRA), which is used in many different fields of study to predict and explain human behaviours that are motivated by rational actions and the intention to control behaviour.

Originally proposed by Davis, TAM has been subject to several modifications tested with the help of different computer systems, such as the WriteOne text editor (Davis et al., 1989), YouTube as a learning resource (Chintalapati et al., 2016), open-source software (Przechlewski, 2012), and the use of mobile apps in higher education (Han Wai et al., 2018). Although TAM has been applied to a great number of areas for modelling the usefulness and the use and adoption of different IT, no studies on AutoCAD could be found (more: Section 3). This gap in the literature for the adoption of AutoCAD as a technology for supporting the engineering work is addressed in the current research.

The purpose of this study is to examine and validate determinants of user intention to use AutoCAD, utilising the constructs from prior studies in a more integrated model. In this research, apart from the two main TAM determinant factors - PU (perceived usefulness) and PEOU (perceived ease of use) - the PPA (perceived physical accessibility) was added to the proposed research model as another determinant of AutoCAD adoption.

The rest of the paper is organised as follows: Section 1 provides an overview of the research background; Section 2 reviews the related works; Section 3 describes the research model and hypotheses; Section 4 presents the data collection procedures and the research method used in this study. Then, results are presented and subsequently discussed. The last section summarises and concludes this paper.

\section{RESEARCH BACKGROUND}

The author's professional and teaching experience shows that although the market offers many computeraided design systems (e.g., SolidWorks, GstarCAD, I-DEAS, Inventor or Fusion), AutoCAD is the most popular. Most university or college engineering study programmes are based on this application. Is this the right choice? What is the adoption of this software among users? How do they perceive its potential as regards the ease of use, usefulness or accessibility? This research was conducted to help answer these questions as well as fill the knowledge gap regarding a model that explains the adoption of AutoCAD among users. Based on the literature review provided in Section 2, the author decided to choose the Technology Acceptance Model as the basis of this study.

\subsection{TAM MODEL}

The Technology Acceptance Model is often used in acceptance analyses of different types of IT solutions. The value of any technology can be best appraised by its users, who only choose to use it if the benefits outweigh the cost. TAM was proposed by Davis in 1986 to explain what motivates people to accept or reject a piece of technology. TAM is derived from the Theory of Reasoned Action (TRA) (Fishbein \& Ajzen, 1975; Ajzen \& Fishbein, 1980), which is a psychological model, according to which any action is preceded by intention (behavioural intention, BI) that is determined by subjective norms and attitudes towards behaviours. TAM is based on two main predictive factors: whether users perceive technology as useful (perceived usefulness - PU) and easy to use (perceived ease of use - PEOU). Davis defined the perceived usefulness as "the degree to which a person believes that using a particular system would enhance his or her job performance," while the perceived ease of use as "the degree to which a person believes that using a particular system would be free from effort" (Davis, 1989, p. 320). These two variables included in the TAM model predict a user approach to technology and the influence on their intention (BI) to accept it and use it. It should be stressed that TAM was subject to many modifications over the years (Davis et al., 1989, p. 985; Davis, 1993, p. 481), to be presented in its final version in 1996 (Venkatesh \& Davis, 1996, p. 453). This study used this version of the model.

Lim (2018) suggested that TAM should be regarded as "a model that increases opportunities to understand the peculiarities of user interactions with technology in contemporary technology-mediated environments, not limiting them." With this suggestion in mind, the purpose of this study was to analyse and understand user relationships with AutoCAD and to extend TAM so as to work up theory and practice.

\subsection{AutoCAD}

AutoCAD was developed by Autodesk as a tool for two-dimensional (2D) and three-dimensional (3D) 
computer-aided designing (CAD). The software is commonly used in many industries by design engineers, mechanics, architects and other designers. It is a closed-source, proprietary, legally reserved program. In other words, it is not only subject to use, copy and modification restrictions, but also licensed to its users for a fee. There are different purchase and access procedures for corporate users and private individuals. Licences are time-limited and offered as monthly, quarterly, annual, two-year and three-year plans. The price to be paid is relatively high and may differ, depending on a region and access type (stationary, mobile, cloud-based, single user or multiple users). Furthermore, there is a trial version with a built-in 30-day time limit. Due to the facts mentioned above and the high cost of the licence, AutoCAD has many strong competitors, e.g. GstarCAD with interfaces and features very similar to AutoCAD. The price of a lifetime licence for GstarCAD is comparable with the monthly cost of the AutoCAD subscription.

The costly AutoCAD licence has become the reason for including a new variable in the TAM model here, namely PPA - the perceived physical accessibility (more: Section 3).

\section{STUDIES ON TAM MODELS}

For an overview of existing studies, papers published in Scopus indexed journals were selected using TAM-related key words in abstracts as a selection criterion. The search query yielded a set of 1419 papers published in the years 1997-2018. First, most frequently cited papers were selected for analysis. Then, attention was given to earlier studies to identify constructs to be used in the proposed model.

The authors with the highest citation index of 1634 (Moon \& Kim, 2001) extended TAM for the WWW context with playfulness as a new factor that reflects the user intrinsic belief in the WWW acceptance. Another interesting and highly cited paper was authored by Venkatesh and Bala (2008) analysing how to enhance employee adoption and use of information technologies at a workplace. Their findings have important implications for managerial decisions as regards IT implementation in organisations. Wu and Wang (2005) analysed what determines mobile commerce user acceptance, adding such additional variables to TAM as risk and cost. The researchers identified the positive influence of perceived risk on behavioural intention to use (BI). TAM was tested in many empirical studies. Table 1 presents the list of studies with a synthetic summary of constructs used in TAM mod- els and the summary of findings. The table also includes three projects from the 1980s due to their relevance to the present study.

Literature analyses show that TAM was tested in many areas. It is highly predictive of the user willingness to use and their acceptance of IT. The existing studies were based on different versions and extensions of TAM. Some of them concentrated on integrating new constructs with proposed models. The overview did not identify any analyses of AutoCAD acceptance. Furthermore, the literature analysis shows a deficit of an essential construct that might address different types of barriers preventing users from using IT. For commercial software, it would be particularly important to include such variable, since the cost of a licence represents the initial barrier to software accessibility. Although the Accessibility construct appears in the analysis of the literature on the use of TAM models (Rice \& Shook, 1988; Thong et al., 2002; Park, 2009), it does not encompass all aspects of what should be included in this variable for AutoCAD or any other commercial software. For this reason, the present study aims to extend the proposed model that analyses the adoption of AutoCAD by adding a new variable - PPA (the perceived physical accessibility). Considering that there has been no construct like this in the existing studies so far, the objective of the work was expanded so as to develop adequate measurement scales.

Perceived accessibility was found to be one of the important determinants of the frequency of using IT (Culnan, 1985). Thong et al. (2002) defined accessibility as the ease with which people can locate specific IT. According to Culnan (1985), accessibility is a multidimensional concept encompassing physical access to IT. Accessibility perception is moderated by different factors, such as the cost of software, physical access restrictions due to the place where users are able to use the installed software (e.g. at work only), or limited time of application accessibility (more: Section 3). The PPA variable added to the model will include such accessibility barriers to this commercial application.

\section{CONCEPTUAL MODEL AND RESEARCH HYPOTHESES}

The main purpose of the TAM is to explain the determining factors in end-user adoption of computer technologies. This research adopted a simplified TAM from Venkatesh and Davis (1996, p. 453) and the new variable PPA (the perceived physical accessibility) was included. Variables in the model: 
Tab. 1. Previous TAM research

\begin{tabular}{|c|c|c|c|}
\hline AUTHORS & CONSTRUCTS & APPLICATIONS & FINDINGS \\
\hline $\begin{array}{l}\text { Rice and } \\
\text { Shook (1988) }\end{array}$ & $\begin{array}{l}\text { Accessibility, USE, Value, Job Type, } \\
\text { Appropriate, Outcomes }\end{array}$ & $\begin{array}{l}\text { Electronic Messaging } \\
\text { System (EMS) }\end{array}$ & $\begin{array}{l}\text { Accessibility } \rightarrow \text { USE, Job Type } \rightarrow \text { USE, } \\
\text { Value } \rightarrow \text { USE, USE } \rightarrow \text { Outcomes }\end{array}$ \\
\hline Davis (1989) & PU, PEOU, USE* & $\begin{array}{l}\text { PROFS - electronic } \\
\text { mail, the XEDIT file } \\
\text { editor, and IBM PC- } \\
\text { systems: Chart-Master, } \\
\text { Pendraw }\end{array}$ & PEOU $\rightarrow$ USE, PU $\rightarrow$ USE \\
\hline $\begin{array}{l}\text { Davis et al. } \\
\text { (1989) }\end{array}$ & PU, PEOU, ATT, BI, USE & WriteOne & $\begin{array}{l}\mathrm{PEOU} \rightarrow \mathrm{PU}, \mathrm{PU} \rightarrow \mathrm{ATT}, \mathrm{PEOU} \rightarrow \mathrm{ATT}, \\
\mathrm{ATT} \rightarrow \mathrm{BI}, \mathrm{BI} \rightarrow \mathrm{USE}, \mathrm{PU} \rightarrow \mathrm{BI}\end{array}$ \\
\hline $\begin{array}{l}\text { Teo et al. } \\
(1999)\end{array}$ & PU, PEOU, USE, PE & Internet & $\begin{array}{l}P E O U \rightarrow P U, P U \rightarrow U S E, P E O U \rightarrow U S E, \\
P E \rightarrow U S E, P E O U \rightarrow P E\end{array}$ \\
\hline $\begin{array}{l}\text { Thong et al. } \\
\text { (2002) }\end{array}$ & $\begin{array}{l}\text { PU, PEOU, BI, System Accessibility (SA), } \\
\text { Terminology, Screen Design, Navigation, } \\
\text { Relevance, System Visibility, Computer } \\
\text { Self-Efficacy (CsE), Computer Experience } \\
\text { (CEx), Domain Knowledge (DK), }\end{array}$ & digital library & $\begin{array}{l}\text { Terminology } \rightarrow \text { PEOU, Screen } \\
\text { Design } \rightarrow \text { PEOU, Navigation } \rightarrow \text { PEOU, } \\
\text { Relevance } \rightarrow \text { PU, System Visibility } \rightarrow \text { PU, } \\
\text { CsE } \rightarrow \text { PEOU, CEx } \rightarrow \text { PEOU, DK } \rightarrow \text { PEOU, } \\
P E O U \rightarrow P U, P E O U \rightarrow B I, P U \rightarrow B I\end{array}$ \\
\hline Park (2009) & $\begin{array}{l}\text { PU, PEOU, ATT, BI, SN System } \\
\text { Accessibility (SA) }\end{array}$ & e-learning & $\begin{array}{l}\mathrm{ATT} \rightarrow \mathrm{BI}, \mathrm{SE} \rightarrow \mathrm{BI}, \mathrm{SN} \rightarrow \mathrm{BI}, \mathrm{PU} \rightarrow \mathrm{ATT}, \\
\mathrm{PEOU} \rightarrow \mathrm{ATT}, \mathrm{SN} \rightarrow \mathrm{ATT}, \mathrm{PEOU} \rightarrow \mathrm{PU}, \mathrm{SE}, \\
\mathrm{SN} \rightarrow \mathrm{PU}, \mathrm{SE} \rightarrow \mathrm{PEOU}, \mathrm{SA} \rightarrow \mathrm{PEOU}\end{array}$ \\
\hline $\begin{array}{l}\text { Liébana- } \\
\text { Cabanillas et } \\
\text { al. (2015) }\end{array}$ & $\begin{array}{l}\mathrm{PC}, \mathrm{PU}, \mathrm{ATT}, \mathrm{BI}, \mathrm{PEOU} \text {, Personal } \\
\text { Innovativeness (PI), }\end{array}$ & $\begin{array}{l}\text { QR mobile payment } \\
\text { system }\end{array}$ & $\begin{array}{l}\mathrm{PC} \rightarrow \mathrm{PU}, \mathrm{ATT} \rightarrow \mathrm{BI}, \mathrm{PU} \rightarrow \mathrm{ATT}, \mathrm{PEOU} \rightarrow \mathrm{PU}, \\
\mathrm{PI} \rightarrow \mathrm{PEOU}, \mathrm{PI} \rightarrow \mathrm{BI}, \mathrm{SN} \rightarrow \mathrm{BI}\end{array}$ \\
\hline $\begin{array}{l}\text { Chintalapati et } \\
\text { al. (2016) }\end{array}$ & PU, PEOU, ATT, BI & YouTube & $\begin{array}{l}\mathrm{PEOU} \rightarrow \mathrm{PU}, \mathrm{PU} \rightarrow \mathrm{ATT}, \mathrm{ATT} \rightarrow \mathrm{BI}, \\
\mathrm{PEOU} \rightarrow \mathrm{ATT}\end{array}$ \\
\hline $\begin{array}{l}\text { Bazelais et al. } \\
\text { (2017) }\end{array}$ & PU, PEOU, USE, ATT, BI & $\begin{array}{l}\text { online learning } \\
\text { technologies for } \\
\text { college students }\end{array}$ & $\begin{array}{l}\mathrm{PEOU} \rightarrow \mathrm{PU}, \mathrm{PU} \rightarrow \mathrm{ATT}, \mathrm{ATT} \rightarrow \mathrm{BI}, \\
\mathrm{PEOU} \rightarrow \mathrm{ATT}\end{array}$ \\
\hline $\begin{array}{l}\text { Park et al. } \\
(2017)\end{array}$ & $\begin{array}{l}\text { Technology Acceptance (TA), PE, ATT, BI, } \\
\text { PU, PEOU, Perceived connectedness } \\
\text { (PCON), PC, Perceived control (PCO), } \\
\text { Perceived cost (PCOST) }\end{array}$ & Internet of Things (IoT) & $\begin{array}{l}\mathrm{ATT} \rightarrow \mathrm{BI}, \mathrm{PU} \rightarrow \mathrm{BI}, \mathrm{PU} \rightarrow \mathrm{ATT}, \mathrm{PEOU} \rightarrow \mathrm{ATT}, \\
\mathrm{PEOU} \rightarrow \mathrm{PU}, \mathrm{PCOST} \rightarrow \mathrm{BI} \mathrm{PCON} \rightarrow \mathrm{PU}, \\
\mathrm{PC} \rightarrow \mathrm{PEOU}, \mathrm{PCON} \rightarrow \mathrm{PEOU}, \mathrm{PC} \rightarrow \mathrm{PU}, \\
\mathrm{PCO} \rightarrow \mathrm{PEOU}\end{array}$ \\
\hline $\begin{array}{l}\text { Ahmad et al. } \\
\text { (2017) }\end{array}$ & $\begin{array}{l}\text { PU, PEOU, Trust (TR), Cost, Social } \\
\text { Influence (SI), Variety of services (VOS), } \\
\text { User intention to adopt eGovernment } \\
\text { (eG), control variables: Gender, Age and } \\
\text { Household income }\end{array}$ & m-government service & $\begin{array}{l}\text { TR } \rightarrow \text { eG, } \mathrm{SI} \rightarrow \mathrm{eG}, \text { Gender } \rightarrow \mathrm{eG}, \text { Age } \rightarrow \mathrm{eG} \text {, } \\
\text { Household income } \rightarrow \mathrm{eG}\end{array}$ \\
\hline $\begin{array}{l}\text { Ul Hassan et } \\
\text { al. (2018) }\end{array}$ & $\begin{array}{l}\text { COST, BI, PU, PEOU, Securuty\&Privacy } \\
\text { (S\&P), ATT, SN, Perceived Behavioural } \\
\text { Control (PBC), Self-Efficacy (SE) }\end{array}$ & Internet banking & $\begin{array}{l}\mathrm{PU} \rightarrow \mathrm{ATT}, \mathrm{PEOU} \rightarrow \mathrm{ATT}, \mathrm{ATT} \rightarrow \mathrm{BI}, \\
\mathrm{SE} \rightarrow \mathrm{PBC}, \mathrm{PBC} \rightarrow \mathrm{BI}, \mathrm{SN} \rightarrow \mathrm{BI}, \mathrm{S} \& \mathrm{P} \rightarrow \mathrm{ATT} \\
\mathrm{TS} \rightarrow \mathrm{PBC}, \mathrm{COST} \rightarrow \mathrm{BI}\end{array}$ \\
\hline $\begin{array}{l}\text { Changchit and } \\
\text { Chuchuen } \\
\text { (2018) }\end{array}$ & $\begin{array}{l}\text { PU, PEOU, Perceived Security (PS), } \\
\text { Perceived Speed of Access (PSA), } \\
\text { Perceived Cost of Usage (PCU) }\end{array}$ & Cloud Computing & $\mathrm{PU} \rightarrow \mathrm{BI}, \mathrm{PEOU} \rightarrow \mathrm{BI}, \mathrm{PS} \rightarrow \mathrm{BI}, \mathrm{PCU} \rightarrow \mathrm{BI}$ \\
\hline $\begin{array}{l}\text { Sangi et al. } \\
\text { (2018) }\end{array}$ & $\begin{array}{l}\text { PU, Communication (C), Cost- } \\
\text { effectiveness (CE), Smartphones usage } \\
\text { (SU), Facebook Usage (FbU) }\end{array}$ & Facebook & $\mathrm{PU} \rightarrow \mathrm{FbU}, \mathrm{C} \rightarrow \mathrm{FbU}, \mathrm{SU} \rightarrow \mathrm{FbU}$ \\
\hline Groß (2018) & $\begin{array}{l}\text { PU, PEOU, USE, PE, ATT, Trust (TR), Social } \\
\text { influence (SI), Satisfaction (SAT) }\end{array}$ & mobile shopping & $\begin{array}{l}\mathrm{PU} \rightarrow \mathrm{ATT}, \mathrm{PE} \rightarrow \mathrm{ATT}, \mathrm{PEOU} \rightarrow \mathrm{ATT}, \mathrm{SI} \rightarrow \mathrm{BI}, \\
\mathrm{PEOU} \rightarrow \mathrm{PU}, \mathrm{PEOU} \rightarrow \mathrm{PE}, \mathrm{ATT} \rightarrow \mathrm{BI}, \mathrm{TR} \rightarrow \mathrm{BI}, \\
\mathrm{BI} \rightarrow \mathrm{USE}, \mathrm{SAT} \rightarrow \mathrm{USE}\end{array}$ \\
\hline
\end{tabular}

*Legend: PEOU - perceived ease of use; PU - perceived usefulness; ATT - attitude; BI - behavioural intention; PE — perceived enjoyment; SN — subjective norms; PC - perceived compatibility. 
- the perceived usefulness (PU), i.e. answers to the following questions: What can the new technology be used for? Will it make my tasks easier to perform?

- the perceived ease of use (PEOU), i.e. the following considerations: Will using the new technology require much work and effort from me?

- the behavioural intention to use (BI) is a measure of the likelihood that a person will employ the application;

- the technology use (USE) - the actual use of the technology;

- the perceived physical accessibility (PPA) is expected to show how the user perceives the accessibility of the technology. By adding this variable, barriers to and difficulties with accessing the software are expected to be included in the model.

AutoCAD is a commercial product and users have to pay for the licence. This implies four perspectives that have been considered by adding the PPA to the model:

- place (including distance) where users may use AutoCAD (PPA1),

- subjective perception of a user of access barriers/ limitations (PPA2);

- cost of obtaining the application (PPA3);

- time (unlimited or limited by, e.g., work/school hours, or using the trial version), when the user may use AutoCAD (PPA4).

The revised TAM is shown in Fig. 1.

The following hypotheses are proposed in the model presented here:

- H1. (PEOU $\rightarrow$ PU) Perceived ease of use has an effect on perceived usefulness.

- H2. (PU $\rightarrow$ BI) Perceived usefulness has an impact on behavioural intention to use.

- $\mathrm{H} 3$. (PEOU $\rightarrow \mathrm{BI}$ ) Perceived ease of use has an effect on behavioural intention to use.



Fig. 1. Proposed research model
- $\quad$ H4. (PPA $\rightarrow$ BI) Perceived physical accessibility has an impact on behavioural intention to use.

- $\quad \mathrm{H} 5$. (BI $\rightarrow$ USE) Behavioural intention to use has an effect on the actual use.

- H6. (PPA $\rightarrow$ USE) Perceived physical accessibility exerts an impact on the actual use.

\section{STUDY DESIGN, DATA COLLEC- TION PROCEDURES AND THE USED RESEARCH METHOD}

The research procedure began with a literature review intended to identify measurement scales for the variables in the model. To ensure that a comprehensive list of scales was included, works of other authors were reviewed. As mentioned before, the latent variable PPA was added to the TAM - a variable, for which the existing literature had not provided any defined and tested measurement scales. To measure PPA, four questions were asked in the questionnaire with the answer scales defined by the author. Table 2 presents a summary of all variables of the model, with the measures used in the analysis.

To collect data needed to perform the analyses and to test the hypotheses, a questionnaire survey was conducted in 2019 in Poland. The online survey was created using the Google Forms service. To begin with, a pilot survey was conducted with respondents who declared extensive experience in using AutoCAD. Its aim was to check how the questionnaire worked in terms of clarity of the questions and whether the instrument captured the elements sought without omitting any important aspects. The questionnaire consisted of five headline questions describing the respondent profile (gender, age, education, job, experience) and five latent variables (each of them in a separate section of the questionnaire).

\subsection{RESPONDENTS}

The survey respondents were recruited from among individuals who had been using AutoCAD for a few months at least. This criterion allowed BSc students ( $81.4 \%$ of the respondents), MSc students (5.4\%), as well as professionally active design engineers who were using AutoCAD in their everyday work.

Students as subjects are appropriate for this type of study as they are certainly part of future target groups for AutoCAD software. As a generation surrounded by and intensively using digital technologies in their life, students can provide a new perspective on the 
Tab. 2. Construct measurement and scale items

\begin{tabular}{|c|c|c|}
\hline VARIABLE & CONSTRUCTS & SOURCE/REFERENCE \\
\hline PEOU & \multicolumn{2}{|l|}{ Perceived eAse of USE } \\
\hline PEOU1 & Learning to use AutoCAD is easy for me & $\begin{array}{l}\text { Igbaria et al. (1997); Karahanna et al. } \\
\text { (2006); Venkatesh et al. (2003) }\end{array}$ \\
\hline PEOU2 & I can easily do what I want and need in AutoCAD & Davis (1989) \\
\hline PEOU3 & My interaction with AutoCAD is clear and understandable & $\begin{array}{l}\text { Karahanna et al. (2006); Venkatesh and } \\
\text { Davis (2000) }\end{array}$ \\
\hline PEOU4 & I can easily use AutoCAD efficiently & $\begin{array}{l}\text { F. D. Davis (1989); Karahanna et al. } \\
\text { (2006) }\end{array}$ \\
\hline PEOU5 & AutoCAD is an intuitive program & Author \\
\hline PU & \multicolumn{2}{|l|}{ Perceived usefulness } \\
\hline PU1 & Using AutoCAD enables me to accomplish tasks more quickly & Davis (1989); Venkatesh et al. (2003) \\
\hline PU2 & Using AutoCAD increases my productivity & Davis (1989); Venkatesh et al. (2003) \\
\hline PU3 & Using AutoCAD enhances my work effectiveness & $\begin{array}{l}\text { Davis (1989); Igbaria et al. (1997); } \\
\text { Venkatesh and Davis (2000) }\end{array}$ \\
\hline PU4 & Using AutoCAD makes it easier to do my job & Karahanna et al. (2006) \\
\hline PU5 & I find AutoCAD useful in my job & $\begin{array}{l}\text { Davis, 1989; Igbaria et al. (1997) } \\
\text { Venkatesh and Davis (2000) }\end{array}$ \\
\hline BI & \multicolumn{2}{|l|}{ BEHAVIOURAL INTENTION } \\
\hline $\mathrm{BI} 1$ & I intend to use AutoCAD in the next six months & Venkatesh et al. (2003) \\
\hline $\mathrm{BI} 2$ & Given that I have access to AutoCAD, I predict that I would use it & Venkatesh and Davis (2000) \\
\hline $\mathrm{BI} 3$ & I will use AutoCAD on a regular basis in the future & Lai and Li (2005) \\
\hline $\mathrm{B} 14$ & I will strongly recommend others to use AutoCAD & Lai and Li (2005) \\
\hline $\mathrm{BI5}$ & I intend to increase my use of AutoCAD in the future & $\begin{array}{l}\text { Agarwal and Prasad (1998); Lai and Li } \\
\text { (2005) }\end{array}$ \\
\hline PPA & \multicolumn{2}{|l|}{ PeRCEIVED PhysicAl ACCESSIBILITY } \\
\hline PPA1 & (distance/place) I can use AutoCAD installed ${ }^{1}$ & Author \\
\hline PPA2 & (difficulty of access) I can access AutoCAD² & Author \\
\hline PPA3 & (cost) Obtaining AutoCAD was ${ }^{3}$ & Author \\
\hline PPA4 & (time) I can use AutoCAD ${ }^{4}$ & Author \\
\hline USE & \multicolumn{2}{|l|}{ ACTUAL USE } \\
\hline USE1 & I use AutoCAD less than once a week & Davis et al. (1989) \\
\hline USE2 & I always use AutoCAD whenever I have a project to do & Author \\
\hline USE3 & I have used AutoCAD in the last six months & Groß (2018) \\
\hline USE4 & I use AutoCAD more than once a day & Davis et al. (1989) \\
\hline USE5 & I use AutoCAD regularly four to six times per week & Davis et al. (1989) \\
\hline
\end{tabular}

* Variables PEOU1-5, PU1-5, BI1-5 and USE1-5 are measured with the five-point Likert scale

11 - on my own computer, 2 - on a friend's computer, 3 - at work, 4 - at the university, 5 - I do not have access

21 - very easy, 2 - easy, 3 - neutral, 4 - difficult, 5 - very difficult

31 - no cost, 2 - nearly no cost, 3 - acceptable cost, 4 - burdensome, 5- very burdensome

${ }^{4} 1$ - without limitations, always, 2 - without limitations at work/at the university, 3 - no opinion, 4 - with limitations at work/at the university,

5 - always with limitations 
Tab. 3. Main characteristics of the sample structure

\begin{tabular}{|r|l|l|}
\hline \multicolumn{2}{|c|}{$59.2 \%$ women } & \multicolumn{1}{|c|}{ THE DISTRIBUTION OF EMPLOYMENT STATUS AMONG THE RESPONDENTS: } \\
\hline \multicolumn{3}{|c|}{ men } \\
\hline $37.6 \%$ & not employed, not looking for a job (full-time students) \\
\hline $25.4 \%$ & employed, working 40 or more hours a week \\
\hline $19.7 \%$ & employed, working 1 - 39 hours a week \\
\hline $17.3 \%$ & self-employment etc. \\
\hline \multicolumn{2}{|c|}{ THE DISTRIBUTION OF RESPONDENTS' EXPERIENCE IN WORK WITH AUTOCAD: } \\
\hline $50 \%$ & using the software for six months \\
\hline $30.5 \%$ & more than six months, up to a year \\
\hline $15.8 \%$ & more than a year, up to five years \\
\hline $3.7 \%$ & more than five years \\
\hline
\end{tabular}

issue. It is, therefore, worth learning their preferences and opinions.

Women accounted for $59.2 \%$ of the survey sample $(\mathrm{n}=347)$, and men - for $40.8 \%$. In the economic reality of our days, it is not uncommon to meet an MSc student who is already working as an engineer. Therefore, it is worthwhile defining the distribution of the employment status among the respondents and the distribution of respondent experiences with AutoCAD. The main characteristics of the sample structure are presented in Table 3.

\subsection{Method}

The study is based on Structural Equation Modelling (SEM). Structural Equation Modelling allows to present the causal structure of phenomena statistically, where:

- many variables can be analysed concurrently,

- the analysed variables can be latent, which means they are not measured directly.

The relationships between the indicator variables are captured in a covariance matrix. The Structural Equations Model consists of two components. The first one - the structural model - describes dependencies between latent variables, while the second component - the measurement model - describes the value of observable variables. The process of structural modelling can be divided into consecutive stages (Hair et al., 2010; Charles \& Kumar, 2014, p. 311):

- data collection;

- model specification;

- identification, which it comes down to answering the question, whether information included in the variance-covariance matrix is sufficient as a basis for estimating the model parameters;

- estimation - minimising a certain function of judging how well the model fits the empirical data (the maximum likelihood method is most commonly used);

- evaluation - comparing differences between the implied variance-covariance matrix and the sample variance-covariance matrix (the function of these differences has the distribution $\chi^{2}$, which allows their significance to be assessed precisely, using an adequate statistical test ${ }^{1}$ );

- modification of the structure of factors and items, if the model fit needs to be improved.

The statistical methods used for the empirical verification of validity and reliability include variance analysis and - first of all - Exploratory Factor Analysis (EFA) and Confirmatory Factor Analysis (CFA). In the confirmatory approach, a theoretical model is the starting point; otherwise, the approach is referred to as exploratory. In practice, these two approaches complement each other. Each exploration is based on an initial model (number of constructs, number of items). A similar process takes place in the confirmatory analysis, and if empirical verification does not support the model assumptions, they are usually modified to obtain a better fit.

\footnotetext{
${ }^{1}$ The research practice shows that model assessment should be based on measuring the value of many indicators $\left(\chi^{2}\right.$, statistics, TLI, Standardised RMR, RMSEA, etc.). Only adopting an approach like this enables the decision to be made whether the model fit is good enough or insufficient.
} 
Tab. 4. Evaluation of the measurement model

\begin{tabular}{|c|r|r|r|r|r|r|r|r|}
\hline FACTOR & \multicolumn{1}{|c|}{ ALPHA } & \multicolumn{1}{c|}{ CR } & \multicolumn{1}{c|}{ AVE } & \multicolumn{1}{c|}{ PEOU } & \multicolumn{1}{c|}{ PU } & BI & PPA & USE \\
\hline PEOU & 0.87 & 0.87 & 0.58 & $\mathbf{0 . 7 6}$ & & & & \\
\hline PU & 0.95 & 0.95 & 0.79 & 0.54 & $\mathbf{0 . 8 9}$ & & & \\
\hline BI & 0.88 & 0.88 & 0,59 & 0.67 & 0.57 & $\mathbf{0 . 7 7}$ & & \\
\hline PPA & 0.84 & 0.80 & 0.51 & -0.16 & -0.26 & -0.03 & $\mathbf{0 . 7 1}$ & \\
\hline USE & 0.86 & 0.86 & 0.55 & 0.33 & 0.35 & 0.31 & -0.36 & $\mathbf{0 . 7 4}$ \\
\hline
\end{tabular}

Note: Chi-square $(242)=501.81 ; \mathrm{CFI}=0.94 ; \mathrm{TLI}=0.93 ; \mathrm{RMSEA}=0.056(90 \% \mathrm{Cl}=0.05-0.06) ; \mathrm{n}=347$.

Values in bold and italic along the diagonal indicate the square root of the average variance extracted (AVE).

Individual scale items should be correlated to a high degree. The internal reliability of a scale ${ }^{2}$ is most often tested by computing coefficient $\alpha$ proposed by Cronbach. Factor analysis of validity is based on two procedures (Charles \& Kumar, 2014, p. 306):

- the analysis of principal components or the principal axis factoring used at the initial stage of the test;

- $\quad$ structural equations modelling (SEM) in a situation where dependencies between measures and factors are theoretically determined.

Using SEM for verifying measurement models is referred to as CFA. Confirmatory factor analysis confirms (or rejects) the hypotheses proposed a priori that specify dependencies between a set of items and individual constructs and at the same time is used for determining the adequacy of measurement scales: their validity and reliability. The procedure of determining the model validity consists of proving that the proposed model fits the data and that factor loadings are statistically significant (statistical value $|t|>1.96$ ).

Fornell and Larcker (1981) proposed a simplified procedure for confirming validity based on average variance extracted (AVE), which is computed using the value of model estimated parameters as a basis. AVE takes a value from the interval $[0 ; 1]$. Validity is considered confirmed if AVE > 0.5, which means that more than $50 \%$ of the item variability is explained by the variability of the latent construct.

Causal relationships between items and latent constructs can be presented using reflective or formative indicators. Przechlewski (2011, p. 65) observes that in social sciences, latent features are much more often measured using the reflective approach, where the construct is considered as a cause and the item as an effect. In formative indicators, causality takes an opposite direction, i.e. an item is a cause and a construct - the effect (Hair et al., 2010, p. 734).

\footnotetext{
2 The internal reliability coefficient is defined as the average correlation coefficient value for individual scale items.
}

\section{RESULTS}

For testing the structural model concerning the relationships among the variables, a path analysis was performed via SPSS and AMOS. The study was carried out following the stages described above. A two-stage analytical approach was adopted: during the first stage, the measurement model was tested for its reliability and validity. In contrast, during the second stage, a structural model was analysed to test the research model of the hypothesis.

\subsection{EFA}

Complete data (347 records) using SPSS were submitted for the EFA (Exploratory Factor Analysis). The analysis proceeded in an exploratory mode to determine how and to what extent the observed variables were linked to their underlying factors.

The obtained KMO (Kaiser-Meyer-Olkin) measure of sampling adequacy $=0.912$ is excellent and indicates that patterns of correlations are relatively compact, and so, factor analysis should yield distinct and reliable factors (Charles \& Kumar, 2014, p. 306). Bartlett's test ( $\mathrm{p}$-value $=0.000)$ is statistically significant.

\subsection{CFA}

Within the framework of SEM, the CFA (Confirmatory Factor Analysis) model represents what has been termed as a measurement model. This step tested if the empirical data confirmed the presumed model. The data obtained were tested for reliability and validity using confirmatory factor analysis. The results are presented in Table 4.

The data set provides sufficient discriminant validity because the square roots of all AVE scores are significantly larger than any other correlation coefficients among all constructs (Fornell \& Larcker, 1981). 
Tab. 5. Parameter estimates for causal paths

\begin{tabular}{|l|r|r|r|c|}
\hline \multicolumn{1}{|c|}{ Structural PATH } & BetA & T-VAlUe & P-VAlUe & Test ReSUlt \\
\hline $\mathrm{H} 1 . \mathrm{PEOU} \rightarrow \mathrm{PU}$ & 0.54 & 8.69 & 0.001 & Supported \\
\hline $\mathrm{H} 2 . \mathrm{PU} \rightarrow \mathrm{BI}$ & 0.31 & 5.54 & 0.001 & Supported \\
\hline $\mathrm{H} 3 . \mathrm{PEOU} \rightarrow \mathrm{BI}$ & 0.51 & 7.91 & 0.001 & Supported \\
\hline $\mathrm{H} 4 . \mathrm{PPA} \rightarrow \mathrm{BI}$ & 0.15 & 2.56 & 0.010 & Supported \\
\hline $\mathrm{H} 5 . \mathrm{BI} \rightarrow$ USE & 0.40 & 4.61 & 0.001 & Supported \\
\hline H6. PPA $\rightarrow$ USE & -0.40 & -3.77 & 0.001 & Supported \\
\hline
\end{tabular}

Note: Chi-square $(245)=486.36 ; \mathrm{CFI}=0.94 ; \mathrm{TLI}=0.94 ; \mathrm{RMSEA}=0.053(90 \% \mathrm{Cl}=0.05-0.06) ; \mathrm{n}=347$.

\subsection{STRUCTURAL EQUATION MODELling (SEM)}

The SEM model was drawn and then, the path structure of the conceptual model was computed using AMOS. The research model was tested with the maximum-likelihood estimation. The t-student statistics were reached, which allowed supporting each of the formulated hypotheses of this study. The obtained results are presented in Table 5. Standardised $\mathrm{RMR}=0.0798$ is correct because it should be $<0.08$. Index Beta shows values of parameters that represent the regression coefficients among the constructs.

As shown in Table 5, all postulated relationships between the constructs were highly significant at $\mathrm{p}<$ 0.001 , with one exception: the relationship between PPA and BI (referring to H4) was statistically significant at $\mathrm{p}<0.010$.

\section{DISCUSSION}

The measurement model test presented a good fit between the data and the proposed measurement model. For instance, the comparative fit index (CFI) value was $0.944 ; \mathrm{CMIN} / \mathrm{df}=1.985 ; \mathrm{TLI}=0.937$; RMSEA $=0.053$. According to Browne and Cudeck (1992), RMSEA value of 0.05 indicates a close fit, while a value of up to 0.08 represents a reasonable fit.

The internal reliability of the model was examined by inspecting Cronbach's alphas and composite reliability (CR). Cronbach's alphas for all variables and CR values were above the recommended level of 0.70 (Akkucuk, 2014; Zarantonello et al., 2015). These results confirmed that the internal consistency of the applied scales was acceptable with composite reliability ranges from 0.80 to 0.95 .

The author also assessed convergent validity by measuring the average variance extracted (AVE). AVE measures the amount of variance for the specified indicators accounted for the latent construct. Higher variance extracted values occur when the indicators are truly representative of the latent construct. The guidelines recommend that the variance extracted value should exceed 0.50 for a construct (Sobh, 2010; Charles \& Kumar, 2014; Zarantonello et al., 2015). The obtained values fulfilled the suggested levels with variance extracted value ranges from 0.51 to 0.79 . This means the existence of sufficient convergent validity of all the measures. This information, together with the strong Cronbach's alphas, provides sufficient evidence for the internal consistency of the measurements.

The author also tested the emergent relationships between variables. Both the perceived ease of use and the perceived usefulness are important factors that encourage behavioural intention of AutoCAD use. The perceived usefulness effect was lower than that for the perceived ease of use. This may suggest that users are willing to accept software based on the ease of use rather than based on the functionalities it offers. One may assume that the CAD software available on the market has similar functionalities, but the ease of use is the feature the user values the most. It may be expressed through, e.g., a user-friendly interface and high intuitiveness of the application. This is consistent with the studies published earlier by Davis, who stated that: "a technology that is easier to use will be seen as more useful" (Davis et al., 1989). The perceived ease of use has the strongest effect on the perceived usefulness $(\beta=0.54$, p-value $=0.001)$. A similar tendency was observed by Chintalapati et al. (2016) when analysing YouTube as a learning source in higher education.

The aim of the current study was to develop a more comprehensive version of the Technology Acceptance Model by adding a new variable - PPA. The intended purpose was to explain how the perceived physical accessibility of AutoCAD influences variables $\mathrm{BI}$ and USE.

The extended model assumes that PPA may have a positive impact on $\mathrm{BI}(\mathrm{H} 4$. PPA $\rightarrow \mathrm{BI}$ ) because easy physical access to software (without any perceptible barriers, such as cost, time, place etc.) translates into 
the positive attitude of a user towards AutoCAD. The second assumption concerns the influence of PPA on the USE, as per hypothesis 6 (PPA $\rightarrow$ USE). If AutoCAD is easily accessible (i.e., no barriers exit), this fact has a positive effect on the actual use of the application. A potential engineer with a certain design assignment and no oppressive or even prohibitive access barriers to AutoCAD, will certainly not be looking for any other CAD software even if the latter is more easily accessible. Users are perfectly capable of evaluating a piece of technology, and they will be using it, provided that benefits outweigh the cost. The tests show that the physical accessibility of software has a significant influence on the behavioural intention of the use of Auto$\mathrm{CAD}$ and its actual usage as well.

To sum up, all hypotheses (H1, H2, H3, H4, H5 and H6) received empirical support. The results of the study (Table 5) can be listed as follow:

- PEOU has a statistically significant effect on PU (H1) - this result suggests that when the perceptible satisfaction of users with the ease of use of AutoCAD grows, the perceived usefulness of the software increases as well. This key link is also revealed and confirmed by the state-of-the-art theories in the TAM;

- $\quad$ PU has a statistically significant relationship with BI (H2) - when the perceived usefulness of AutoCAD increases, the positive attitude of users towards the software becomes stronger as well;

- PEOU has a statistically significant effect on BI (H3) - when the perceptible satisfaction of users with the ease of use of AutoCAD grows, user intentions to use the software become stronger;

- PPA exerts a statistically significant impact on BI (H4) - when users do not experience barriers to AutoCAD accessibility, their positive attitude towards AutoCAD grows stronger;

- BI has a statistically significant effect on the USE (H5) - when the positive attitude of users towards AutoCAD grows stronger, the actual use of the application increases;

- $\quad$ PPA exerts a statistically significant impact on the USE (H6) - physical accessibility of the application (fewer access barriers) translates into its greater actual use.

\section{CONCLUSIONS, LIMITATIONS AND FUTURE RESEARCH}

To the knowledge of the author, this was the first study to explore the TAM within the AutoCAD software context. It was also the first effort to empirically

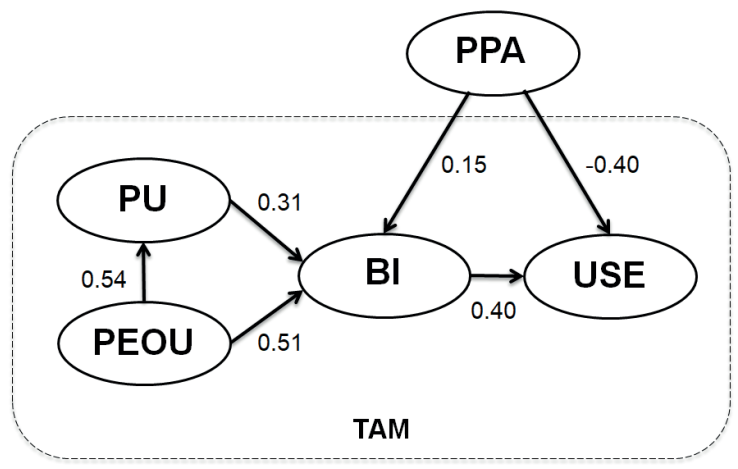

Fig. 2. Extended model TAM of the user attitude towards AutoCAD software with the path structure estimation

validate this extended model. The originality of the present study lies in examining the impact of perceived physical accessibility of AutoCAD on other factors in the TAM, using SEM framework, thus contributing to a new direction of research in the field.

The proposed model (Fig. 2) shows the importance of the PPA variable (AutoCAD accessibility) and proves its significant effect on the variables $\mathrm{BI}$ and the USE. Thus, the empirical findings have demonstrated that adding PPA to the TAM model has been a worthwhile extension. The analysis proved that besides PU and PEOU, the PPA construct became another determinant of the AutoCAD adoption. The effect of PPA on $\mathrm{BI}$ and the USE seemed to be obvious but required empirical confirmation.

Business informatics lack commonly recognised measurement scales. The scales for measuring latent constructs PU and PEOU have been verified many times and are used in general. However, they were an exception in this case. As compared with psychology, for example, where SEM is used, achievements are not particularly impressive in the area covered by the subject of this study. For this reason, the fact of turning attention to such an important element as PPA, confirming its effect on BI and the USE and developing adequate measurement scales was the added value contributed by this study.

The research project presented here was subject to certain limitations that should be considered. Namely, a high share of students in the research sample was one of the major limitations. Possibly, the findings might have differed with proportional representation of different age groups. Possibly, older and more "mature" respondents could have shown more experience with and competence using AutoCAD. Hence, should one change the respondent selection criterion from a few months to a few years of work with this software, the research results might be different. Students, often used as convenience sample respondents in TAM stud- 
ies, are not exactly like either of the other two groups: professionals and general users. Yet, considering the work by King and $\mathrm{He}$ (2006), one may assume that students may be used as substitutes for professional but not "general" users. The author should like to emphasise that the sample for the current study was selected respecting this finding.

The primary objective of the study was to extend the basic TAM model by adding the PPA variable. The focus of future research will be on further expansion of the model by incorporating other variables and testing different IT, as well as by considering different areas of TAM application.

Finally, it would be interesting to investigate the proposed model under different conditions to check its functionality.

\section{LITERATURE}

Agarwal, R., \& Prasad, J. (1998). A conceptual and operational definition of personal innovativeness in the domain of information technology. Information Systems Research, 9(2), 204-215.

Ahmad, S. Z., \& Khalid, K. (2017). The adoption of Mgovernment services from the user's perspectives: Empirical evidence from the United Arab Emirates. Journal of Information Management, 37(5), 367-379.

Ajzen, I., \& Fishbein, M. (1980). Understanding Attitudes and Predicting Social Behavior. Englewood Cliffs, United States: Prentice-Hall.

Akkucuk, U. (Ed.) (2014). Handbook of Research on Developing Sustainable Value in Economics. Finance and Marketing. United States: IGI Global.

Bazelais, P., Doleck, T., \& Lemay, D. J. (2017). Investigating the predictive power of TAM: A case study of CEGEP students' intentions to use online learning technologies. Education and Information Technologies, 23(1), 93-111. doi: 10.1007/s10639-017-9587-0

Browne, M. W., \& Cudeck, R. (1992). Alternative ways of assessing model fit. In: K. A. Bollen \& J. S. Long (Eds.), Testing structural equation models. Newbury Park, United States: Sage Publications.

Changchit, C., \& Chuchuen, C. (2018). Cloud computing: An examination of factors impacting users' adoption. Journal of Computer Information Systems, 58(1), 1-9.

Charles, V., \& Kumar, M. (2014). Performance Measurement and Management. Cambridge, United Kingdom: Scholars Publishing.

Chintalapati, N., \& Daruri, V. S. K. (2016). Examining the Use of YouTube as a Learning resource in higher education: Scale development and Validation of TAM model. Telematics and Informatics, 34(6), 853-860. doi: 10.1016/j.tele.2016.08.008

Culnan, M. J. (1985). The Dimensions of Perceived Accessibility to Information: Implications for the Delivery of Information Systems and Services. Journal of the American Society of Information Sciences, 36, 302-308.

Davis, F. D. (1986). A Technology Acceptance Model for Empirically Testing New End-User Information Systems:
Theory and Results. Cambridge, United States: MIT Sloan School of Management.

Davis, F. D. (1989). Perceived Usefulness, Perceived Ease Of Use, And User Acceptance Of Information Technology. MIS Quarterly, 13(3), 319-340. doi: $10.2307 / 249008$

Davis, F. D. (1993). User Acceptance of Information Technology: System Characteristics, User Perceptions and Behavioral Impacts. International Journal of Man-Machine Studies, 38(3), 475-487. doi: 10.1006/ imms.1993.1022

Davis, F. D., Bagozzi, R., \& Warshaw, P. (1989). User acceptance of computer technology: a comparison of two theoretical models. Management Science, 35(8), 982-1003.

Fishbein, M., \& Ajzen, I. (1975). Belief, Attitude, Intention, and Behavior: An Introduction to Theory and Research. Reading, United States: Addison-Wesley.

Fornell, C., \& Larcker, D. (1981). Evaluating structural equation models with unobservable variables and measurement errors. Journal of Marketing Research, $18,39-50$.

Groß, M. (2018). Heterogeneity in consumers' mobile shopping acceptance: A finite mixture partial least squares modelling approach for exploring and characterising different shopper segments. Journal of Retailing and Consumer Services, 40, 8-18.

Hair, J. F., Black, B., Babin, B., Anderson, R. E., \& Tatham, R. L. (2010). Multivariate Data Analysis. Prentice Hall International.

Igbaria, M., Zinatelli, N., Cragg, P., \& Cavaye, A. L. M. (1997). Personal computing acceptance factors in small firms: A structural equation model. MIS Quarterly, 21(3), 279-305.

Karahanna, E., Agarwal, R., \& Angst, C. M. (2006). Reconceptualizing compatibility beliefs in technology acceptance research. MIS Quarterly, 30(4), 781-804.

King, W. R., \& He, J. (2006). A meta-analysis of the technology acceptance model. Information and Management, 43(6), 740-755.

Lai, V. S., \& Li, H. (2000). Technology acceptance model for internet banking: An invariance analysis. Information and Management, 42(2), 373-386.

Liébana-Cabanillas, F., Ramos de Luna, I., \& Montoro-Ríos, F. J. (2015). User behaviour in QR mobile payment system: the QR Payment Acceptance Model. Technology Analysis \& Strategic Management, 27(9), 1031-1049. doi: 10.1080/09537325.2015.1047757

Lim, W. M. (2018). Dialectic Antidotes to Critics of the Technology Acceptance Model: Conceptual, Methodological, and Replication Treatments for Behavioural Modelling in Technology-Mediated Environments. Australasian Journal of Information Systems, 22, 1-11. doi: 10.3127/ajis.v22i0.1651

Moon, J. W., \& Kim, Y. G. (2001). Extending the TAM for a World-Wide-Web context. Information and Management, 38, 217-230.

Park, E., Cho, Y., Han J., \& Kwon, S. J. (2017). Comprehensive Approaches to User Acceptance of Internet of Thingsin a Smart Home Environment. IEEE Internet of Things Journal, 4(6), 2342-2350.

Park, S. Y. (2009). An Analysis of the Technology Acceptance Model in Understanding University Students' Behavioral Intention to Use e-Learning. Educational Technology \& Society, 12(3), 150-162. 
Przechlewski,T.(2012).Modelowaniesatysfakcji, użyteczności i wykorzystania oprogramowania Open Source [Modeling the satisfaction, usability and use of Open Source software]. Gdańsk, Poland: Wydawnictwo Uniwersytetu Gdańskiego.

Rice, R. E., \& Shook, D. (1988). Access to, Usage of, and Outcomes from an Electronic Message System. ACM Transactions on Office Information Systems, 6(3), 255-276.

Sangi, N., Shuguang, L., \& Sangi, A. R. (2018). Robustness of factors influencing social media usage/adoption amongst SMEs in developing countries: A case of Pakistan. ACM International Conference Proceeding Series, 103-109. doi: 10.1145/3183586.3183600

Sobh, T. (ed.), (2010). Innovations and Advances in Computer SciencesandEngineering.Switzerland:SpringerScience \& Business Media.

Teo, T. S. H., Lim, V. K. G., \& Lai, R. Y. C. (1999). Intrinsic and extrinsic motivation in internet usage. Omega, 27(1), 25-37.

Thong, J. Y. L., Hong, W., \& Tam, K. (2002). Understanding user acceptance of digital libraries: What are the roles of interface characteristics, organizational context, and individual differences? International Journal of Human-Computer Studies, 57, 215-242.

Ul Hassan, M., Iqbal, A., \& Iqbal, Z. (2018). Factors affecting the adoption of internet banking in Pakistan: An integration of technology acceptance model and theory of planned behaviour. International Journal of Business Information Systems, 28(3), 342-370.

Venkatesh, V., \& Bala, H. (2008). Technology acceptance model 3 and a research agenda on interventions. Decision Sciences, 39(2), 273-315.

Venkatesh, V., \& Davis, F. D. (1996). A Model of the Antecedents of Perceived Ease of Use: Development and Test. Decision Sciences, 27(3), 451-481. doi: 10.1111/ j.1540-5915.1996.tb01822.x

Venkatesh, V., \& Davis, F. D. (2000). A theoretical extension of the technology acceptance model: four longitudinal field studies. Management Science, 46(2), 186-204.

Venkatesh, V., Morris, M. G., Davis G. B., \& Davis F. D. (2003). User acceptance of information technology: toward a unified view. MIS Quarterly, 27(3), 425-478.

Wai I. S. H., Ng S. S. Y., Chiu D. K. W., Ho K. K. W., \& Lo P. (2018). Exploring undergraduate students' usage pattern of mobile apps for education. Journal of Librarianship and Information Science, 50(1), 34-47.

Wu, J. H., \& Wang, S. C. (2005). What drives mobile commerce? An empirical evaluation of the revised technology acceptance model. Information and Management, 42, 719-729.

Zarantonello, L.,\&Pauwels-Delassus, V.(2015). TheHandbook of Brand Management Scales. New York, United State: Taylor \& Francis Group. 